\title{
Photocatalytic activity of spectro-pure titanium dioxide: Effects of crystalline structure, specific surface area and sorption properties
}

\author{
Evgeny I. Kapinus, Tatyana A. Khalyavka, Valentina V. Shimanovskaya, \\ Tatyana I. Viktorova, and Vladimir V. Strelko \\ Institute for Sorption and Probems of Endoecology, Ukrainian National Academy of Sciences, \\ 13, General Naumov Str., Kiev, 03164, Ukraine
}

\begin{abstract}
Dispersed optically pure anatase, rutile and two-phase samples of titanium dioxide were prepared using a sol-gel technique. In particle of two-phase samples, the anatase nuclei are surrounded by a rutile envelope. Content of anatase in the two-phase particles varied between 20 and $80 \%$. Particles of all the $\mathrm{TiO}_{2}$ samples had a globular shape of diameter between 10 and $30 \mu \mathrm{m}$. When compared to the corresponding technical-grade samples, the optically pure anatase and rutile demonstrated higher photocatalytic activity in the destruction of tetradecylpyridinium chloride, Methylene Blue and tetrachlorofluorescein as well as in reduction of $\mathrm{Cr}_{2} \mathrm{O}_{7}{ }^{2-}, \mathrm{MnO}_{4}{ }^{-},\left[\mathrm{Fe}(\mathrm{CN})_{6}\right]^{3-}$ and $\left[\mathrm{Fe}(\mathrm{CN})_{6}\right]^{4-}$. The photocatalytic reactions bring about the reduction of the inorganic anions to yield water insoluble substances and mineralization of the organic compounds. Rate constant of the all above processes do not depend on specific surface area of $\mathrm{TiO}_{2}$ and adsorption of the substrates on the $\mathrm{TiO}_{2}$ samples. The rutile calcined at $1027 \mathrm{~K}$ exhibits the highest specific rate constants. Exposure to $\gamma$-radiation increases photocatalytic activity of the dispersed $\mathrm{TiO}_{2}$. The influence of $\mathrm{TiO}_{2}$ and substrate on the photocatalytic reactions is caused by the influence of these factors on the formation of reactive electron hole pair and on the efficiency of the interfacial electron transfer.
\end{abstract}

\section{INTRODUCTION}

Photocatalytic reactions of organic or inorganic compounds on wide-bandgap semiconductors can be used for the destruction (mineralisation) of water contaminants [1-3]. Nowadays, among the various semiconductors studied, titanium dioxide dispersed or in the form of film is thought as one promising photocatalytic agent because of its high activity in combination with nontoxicity, high stability and availability. Much work has been carried out on kinetics and mechanisms of the photocatalytic processes assisted by $\mathrm{TiO}_{2}$. However, conflicting conclusions may be encounted in literature about the correlation between photocatalytic activity and crystalline structure of $\mathrm{TiO}_{2}$. The following examples can be given as an illustration. Thus, anatase is more active as compared with rutile in the destruction of organic dyes $[4,5]$ but rutile shows higher activity in the photocatalytic mineralisation of trichloroethylene [6]. Opinions differ also widely about influence of sorption properties of titanium dioxide on its photocatalytic activity. Likewise little work has been carried out on the association between efficiency of the photocatalytic process and specific surface area of the dispersed $\mathrm{TiO}_{2}$. Here we present a study of the effects of adsorption properties, specific surface area and crystalline structure on photocatalytic activity of the dispersed $\mathrm{TiO}_{2}$ in mineralisation of tetradecylpyridinium chloride, ${ }^{1}$ Methylene Blue, tetrachlorofluorescein as

\footnotetext{
1 Abbreviations: $\mathrm{TDPy}^{+} \mathrm{Cl}^{-}$-tetradecylpyridinium chloride; $\mathrm{MB}^{+} \mathrm{Cl}^{-}$-Methylene Blue; TCF-tetrachlorofluorescein; A-anatase;
}

well as in reduction of $\mathrm{MnO}_{4}{ }^{-}, \mathrm{Cr}_{2} \mathrm{O}_{7}{ }^{2-},\left[\mathrm{Fe}(\mathrm{CN})_{6}\right]^{3-}$ and $\left[\mathrm{Fe}(\mathrm{CN})_{6}\right]^{4-}$.

The basic principles of heterogeneous photocatalysis on $\mathrm{TiO}_{2}$ can be summarized shortly as follows [2, 3 , 18]. Photoexcitation of the semiconductor leads to the formation of the unreactive (1) or reactive (2) electron holes pair. For colloidal $\mathrm{TiO}_{2}$, the hole trapping occurs in a few hundred nanoseconds, whereas electron trapping processes in the picoseconds time frame

$$
\begin{aligned}
& \mathrm{TiO}_{2}+h v \longleftrightarrow \mathrm{e}_{\mathrm{tr}}{ }^{-}+\mathrm{h}_{\mathrm{tr}}{ }^{+}, \\
& \mathrm{TiO}_{2}+h v \longleftrightarrow \mathrm{e}_{\mathrm{r}}{ }^{-}+\mathrm{h}_{\mathrm{r}}{ }^{+} .
\end{aligned}
$$

The electron, $\mathrm{er}^{-}$, and the hole, $\mathrm{h}_{\mathrm{r}}{ }^{+}$, can recombine on the surface or in the bulk of the particle in few nanoseconds

$$
\mathrm{e}_{\mathrm{r}}^{-}+\mathrm{h}_{\mathrm{r}}{ }^{+} \longrightarrow h v \text { or heat, }
$$

or can be trapped by acceptor (A) or donor (D) on the surface of the particle

$$
\begin{gathered}
\mathrm{e}_{\mathrm{r}}^{-}+\mathrm{O}_{\mathrm{x}} \longrightarrow \mathrm{O}_{\mathrm{x}}^{{ }^{--}}, \\
\mathrm{h}_{\mathrm{r}}^{+}+\mathrm{Red} \longrightarrow \mathrm{Red}^{\bullet+} .
\end{gathered}
$$

In the absence of the suitable electron acceptors or hole scavengers, the electron-hole recombination represents the energy dissipation route.

R-rutile; X\%A Y\%R-the two-phase titanium dioxide containing X and $Y$ percentages of anatase and rutile, respectively. 
The photocatalytic degradation of organic materials in aqueous solutions by $\mathrm{TiO}_{2}$ in the presence of oxygen seems to originate from the generation of hydroxide or superoxide radicals which react with substrates or the radical ions derived from the substrates

$$
\begin{gathered}
\mathrm{O}_{2}+\mathrm{e}_{\mathrm{r}}{ }^{-} \longrightarrow \mathrm{O}_{2}{ }^{\bullet-}, \\
\mathrm{H}_{2} \mathrm{O}+\mathrm{h}_{\mathrm{r}}{ }^{+} \longrightarrow \mathrm{OH}^{\bullet}+\mathrm{H}^{+} .
\end{gathered}
$$

Hydroxide radicals are also generated in oxidation of surface hydroxyls by $\mathrm{h}^{+}$

$$
\equiv \mathrm{Ti}-\mathrm{OH}+\mathrm{h}_{\mathrm{r}}{ }^{+} \longrightarrow \equiv \mathrm{Ti}^{+}+\mathrm{OH}^{\bullet} .
$$

It is well known that doping titania with metal transition ions can have a profound impact on the photogeneration of the electrons and holes in the $\mathrm{TiO}_{2}$ lattice (see, for example, [7]). Deposition of transition metal ions onto $\mathrm{TiO}_{2}$ may trigger electron or hole trapping that plagues analysis of influence crystalline structure, specific surface area and other physicochemical factors on photocatalytic activity of $\mathrm{TiO}_{2}$. Therefore, the spectro-pure samples of $\mathrm{TiO}_{2}$ studied in this work enable to compare photocatalytic behavior of various $\mathrm{TiO}_{2}$ samples.

\section{EXPERIMENTAL}

2.1. Preparation and investigation of the $\mathrm{TiO}_{2}$ samples. The optically pure $\mathrm{TiO}_{2}$ was prepared by thermal hydrolysis of titanium tetrachloride in hydrochloric acids solutions in the presence of the anatase or rutile nuclei by the procedure proposed in [8-10], which allow to keep stray ions to a minimum in all the titanium dioxide modifications. Addition of anatase nuclei, results in the optically pure anatase or in the two-phase titanium dioxide with the anatase nuclei and the rutile envelope depending on synthesis conditions. Content of anatase in the two-phase particles was varied between 20 and $80 \%$ that was determined with the help of X-ray analysis.

After synthesis, the $\mathrm{TiO}_{2}$ samples were calcined at 473,573 and $1073 \mathrm{~K}$ followed by washing by water and dried at $473 \mathrm{~K}$ for 48 hours. The content of stray ions (Fe, $\mathrm{Co}, \mathrm{Cr}, \mathrm{Ni}, \mathrm{Cu}, \mathrm{Mn}, \mathrm{V}$ ) in the prepared materials did not exceed $10^{-5} \%$.

The $\mathrm{TiO}_{2}$ particles had a globular shape of diameter between 10 and $30 \mu \mathrm{m}$. Specific surface area in the range fell 3 to $200 \mathrm{~m}^{2} / \mathrm{g}$. Part of the $\mathrm{TiO}_{2}$ samples was irradiated with $\gamma$-rays in a setup with ${ }^{60} \mathrm{Co}$ as the gammaemitter. Dose power was $4.3 \times 10^{-2} \mathrm{~Gy} / \mathrm{s}$.

2.2. Sorption and photolysis procedures. Adsorption of the substrates by $\mathrm{TiO}_{2}$ from aqueous solutions was studied by the standard procedure [11]. Concentrations of the substrates in solutions were measured spectrophotometrically. Experimental relative error for determination of adsorbed substrate, $a$, was within $10 \%$.
The light source for the photodegradation experiments was the low-pressure mercury lamp BUV-30 (30 W, Ukraine) which emits about $83 \%$ light energy at $253.6 \mathrm{~nm}$. The photocatalytic reactor was a quartz tube of $2.5 \mathrm{~cm}$ across provided with a stirrer. Rotation speed was $120 \mathrm{vpm}$. The reactor was $1 \mathrm{~cm}$ distant from the lamp. In the photocatalytic experiments, concentration of $\mathrm{TDP}^{+} \mathrm{Cl}^{-}$and the dyes was $0.09 \mathrm{~g} / \mathrm{l}$ and $0.03 \mathrm{~g} / \mathrm{l}$, respectively. Concentration of $\mathrm{K}_{2} \mathrm{Cr}_{2} \mathrm{O}_{7}$ was $0.06 \mathrm{~g} / \mathrm{dm}^{3}$ and that of $\mathrm{KMnO}_{4}, \mathrm{~K}_{3}\left[\mathrm{Fe}(\mathrm{CN})_{6}\right]$ and $\mathrm{K}_{4}\left[\mathrm{Fe}(\mathrm{CN})_{6}\right]$ was $0.3 \mathrm{~g} / \mathrm{dm}^{3}$. The solid/liquid ratio was about $1: 170$.

Prior UV irradiation, the $\mathrm{TiO}_{2}$ suspension in substrate solution was magnetically stirred in the dark to attain the adsorption/desorption equilibrium between the substance and the $\mathrm{TiO}_{2}$ particles. Sorption and kinetics of the photocatalytic reactions were studied at pH 3 apart from specified experiments.

The reaction products were analyzed by $\mathrm{UV},{ }^{1} \mathrm{H}$ NMR spectroscopy (Varian 300) and mass-chromatography (INCOS 50, Finnigan Corporation.)

\section{RESULTS}

3.1. Sorption of the substrates on $\mathrm{TiO}_{2}$. Sorption of the substrates has been studied with the object of understanding implications of sorption for the photocatalytic reactions. Sorption kinetics was exponential for the majority of the $\mathrm{TiO}_{2}$ samples regardless of their crystalline structure. The time taken to the attainment of the sorption equilibrium was defined by substrate rather than crystalline structure of the $\mathrm{TiO}_{2}$ sample. The equilibrium was reached in 35,2 and $0.5 \mathrm{~h}$ for $\mathrm{TDPy}^{+} \mathrm{Cl}^{-}, \mathrm{MB}^{+} \mathrm{Cl}^{-}$and TCF, respectively. The sorption capacity of anatase was about one order of magnitude higher compared to rutile. Sorption capacity of the two-phase samples depended only slightly on the anatase/rutile ratio. The samples bearing 65\% anatase demonstrated the highest sorption capacity among the two-phase samples, which was close to that of anatase.

Sorption of $\mathrm{TDPy}^{+} \mathrm{Cl}^{-}$and $\mathrm{MB}^{+} \mathrm{Cl}^{-}$on anatase occurred in two stages. In the course of the first one with duration of about 10 hours, anatase absorbs about 90\% of the substrate amount, which can be adsorbed in the given experimental conditions. Length of the second sorption stage exceeded $20 \mathrm{~h}$. The two-step kinetics was also noted for sorption of $\mathrm{MB}^{+} \mathrm{Cl}^{-}$on anatase.

Sorption of the $\mathrm{TDPy}^{+}$and $\mathrm{MB}^{+}$cations decreased as $\mathrm{pH}$ solution is reduced (Figure 1(a)). By contrast, sorption of the anions $\mathrm{Cr}_{2} \mathrm{O}_{7}{ }^{2-}$, $\left[\mathrm{Fe}(\mathrm{CN})_{6}\right]^{3-}$ or $\mathrm{MnO}_{4}{ }^{-}$ increases with decreasing pH (Figure 1(b)). The influence of $\mathrm{pH}$ on sorption of the indicated substrates can be derived from amphoteric nature of the $\mathrm{OH}$ groups on the $\mathrm{TiO}_{2}$ surface. At all pH, correlation between $a$ and specific surface area is lucking for sorption of $\mathrm{TDPy}^{+}$ and $\mathrm{MB}^{+}$on anatase, rutile and the two-phase modification. 

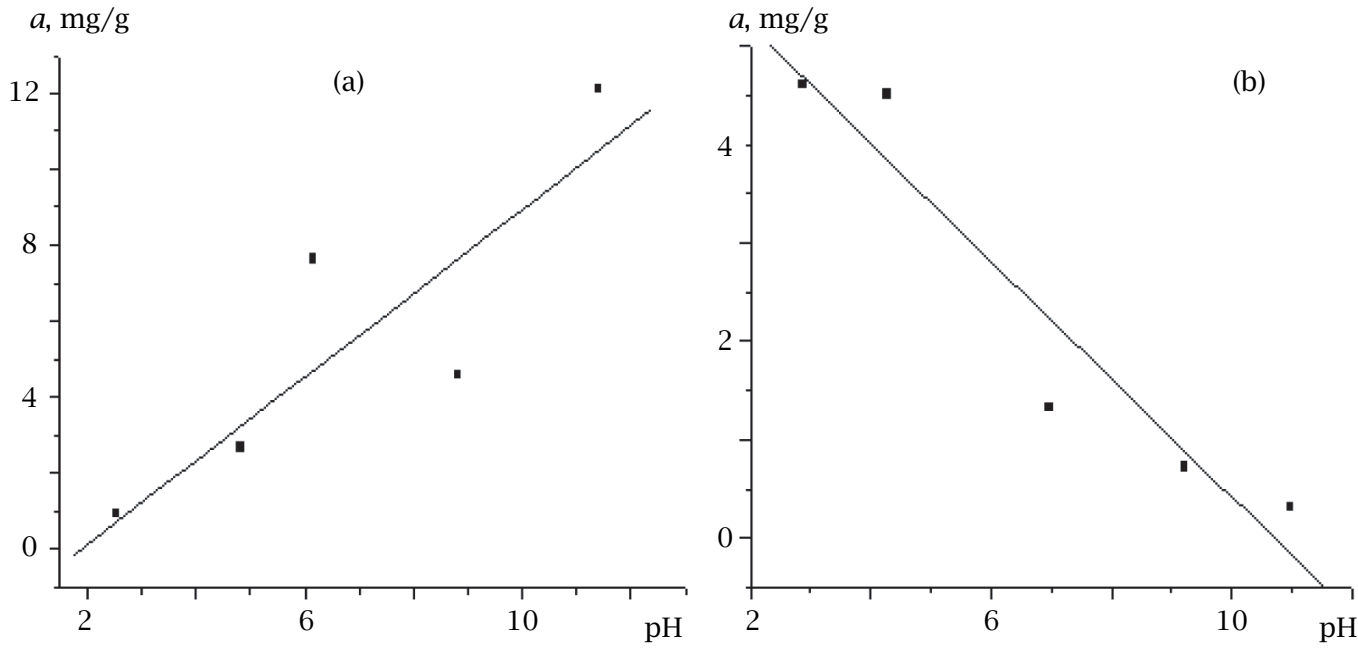

Figure 1. The $\mathrm{pH}$ dependences of adsorption of $\mathrm{TDPy}^{+} \mathrm{Cl}^{-}$(a) and inorganic anions (b) on anatase.

Sorption isotherms for all the above compounds relative to the L-type (Langmuir type) in terms of the Giles classification [12]. The $\mathrm{L}_{2}$-isotherms, taking hyperbolic form, describe sorption of all the substrates on rutile and on the two-phase $\mathrm{TiO}_{2}$ with the anatase content less than $60 \%$ as well as sorption of $\mathrm{MB}^{+} \mathrm{Cl}^{-}$, $\left[\mathrm{Fe}(\mathrm{CN})_{6}\right]^{3-}$ and $\mathrm{TDPy}^{+} \mathrm{Cl}^{-}$on anatase (Figure 2). The isotherms, which do not exhibit a plateau area, govern sorption of TCF, $\mathrm{MnO}_{4}{ }^{-}, \mathrm{Cr}_{2} \mathrm{O}_{7}{ }^{2-}$ on anatase and on the two-phase $\mathrm{TiO}_{2}$, containing above $60 \%$ anatase.

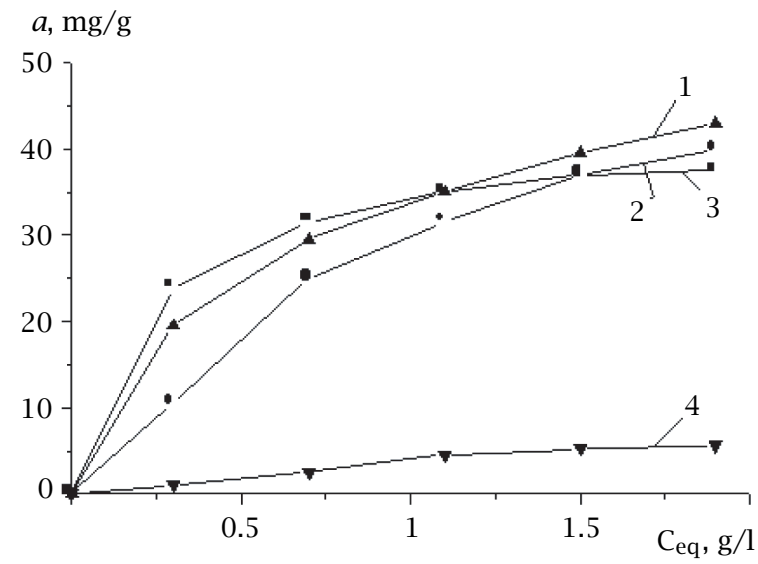

Figure 2. Isotherms of $\mathrm{TDPy}^{+} \mathrm{Cl}^{-}$adsorption on the dispersed titanium dioxide. 1-65\%A 35\%R, 2-75\%A 25\%R, 3-A, 4-R.

3.2. Products of the photochemical and photocatalytic reactions in aqueous solutions $\mathrm{TDPy}^{+} \mathrm{Cl}^{-}$. UV irradiation of $\mathrm{TDPy}^{+} \mathrm{Cl}^{-}$in aqueous solutions during 3 hours resulted in a yellow compound, which was tolerant to UV light over the course of 20 hours. This product, however, being unstable in dark in the presence of oxygen, is converted into initial compound. Conceivably, the product being discussed is formed in the photochemical reduction of the $\mathrm{TDPy}^{+}$cations to form neutral radicals TDPy ${ }^{\bullet}$. Recombination of the latter can yield yellow bipyridinium compound in the presence of oxygen [13].

Irradiation of $\mathrm{TDPy}^{+} \mathrm{Cl}^{-}$in aqueous solution of in the presence of $\mathrm{TiO}_{2}$ produces the destruction of both the pyridinium ring and the long aliphatic chain that was evident from the ${ }^{1} \mathrm{H}$ NMR spectra of the reaction products. Thus the ${ }^{1} \mathrm{H}$ NMR spectrum of the products, isolated from reaction mixture after 3 hour irradiation, displayed only the signals belonging to lower alcohols, ketones and aldehydes.

3.3. $\mathrm{MB}^{+} \mathrm{Cl}^{-}$and TCF. UV irradiation of $\mathrm{MB}^{+} \mathrm{Cl}^{-}$ in water over 3 hours initiates very small destruction of the dye. In the presence of $\mathrm{TiO}_{2}$, total bleaching of $\mathrm{MB}^{+} \mathrm{Cl}^{-}$solution takes place in 3 hours. This photocatalytic reaction is partial reversible. Regeneration of $\mathrm{MB}^{+}$ occurred in part after separation of aqueous solution from $\mathrm{TiO}_{2}$. The reversible product is Leucomethylene Blue in concordance with [17]. The total mineralization of the dye occurs in a consequence of subsequent reactions of the leuco compound that is evident from the following data. A fraction of irreversible products of the photocatalytic reaction increased with increasing duration of UV irradiation. Thus about $80 \%$ MB is regenerated after 3 hours irradiation. The destruction of all amount of the dye occurred in 40 hours UV irradiation. $N, N$-Dimethyl-1,4-phenylenediamine, phenol and carbon oxides were found among the products of the $\mathrm{MB}^{+} \mathrm{Cl}^{-}$destruction using mass-chromatography.

Total destruction of TCF occurs in the course of 3 hours under UV irradiation. Addition of the photocatalyst accelerated the destruction in 6 times.

3.4. Inorganic anions. Aqueous solution of potassium dichromate is inconvertible under the action of UV irradiation. In the presence of $\mathrm{TiO}_{2}$, irradiation of the 
Table 1. Photocatalytic activity of the $\mathrm{TiO}_{2}$ modifications in the destruction of $\mathrm{TDPy}^{+} \mathrm{Cl}^{-}$.

\begin{tabular}{lcccc}
\hline $\mathrm{TiO}_{2}$ samples & Temperature of calcination, $\mathrm{K}$ & $\mathrm{S}_{\mathrm{sp}}, \mathrm{m}^{2} / \mathrm{g}$ & $\mathrm{k}_{\mathrm{d}}\left(\times 10^{4}\right), \mathrm{s}^{-1}$ & $\mathrm{k}_{\mathrm{d}} / \mathrm{S}_{\mathrm{sp}}, \mathrm{gs}^{-1} \mathrm{~m}^{-2}$ \\
\hline $\mathrm{A}$ & 473 & 95 & 1.5 & 0.0158 \\
$\mathrm{~A}$ & 473 & 305 & 1.4 & 0.0046 \\
$\mathrm{~A}$ & 493 & 214 & 0.9 & 0.0042 \\
$\mathrm{~A}$ & 493 & 313 & 0.6 & 0.0019 \\
$\mathrm{~A}$ & 473 & 199 & 1.5 & 0.0075 \\
$\mathrm{R}$ & 1273 & - & 2.2 & - \\
$\mathrm{R}$ & 473 & 95 & 1.2 & 0.0126 \\
$\mathrm{R}$ & 1123 & - & 1.9 & - \\
$\mathrm{R}$ & 1123 & 3 & 1.8 & 0.633 \\
$19 \% \mathrm{~A}$ 81\%R & 773 & 54 & 1.1 & 0.0204 \\
$25 \% \mathrm{~A} 75 \% \mathrm{R}$ & 473 & 197 & 0.7 & 0.0036 \\
$40 \% \mathrm{~A} 60 \% \mathrm{R}$ & 473 & 93 & 0.4 & 0.0043 \\
$65 \% \mathrm{~A} 35 \% \mathrm{R}$ & 573 & 195 & 1.0 & 0.0051 \\
$67 \% \mathrm{~A} 33 \% \mathrm{R}$ & 573 & 183 & 0.6 & 0.0033 \\
$75 \% \mathrm{~A}$ 25\%R & 573 & 185 & 1.1 & 0.0059 \\
$80 \% \mathrm{~A}$ 20\%R & 623 & 165 & 0.7 & 0.0042 \\
\hline
\end{tabular}

Table 2. Photocatalytic activity of the $\mathrm{TiO}_{2}$ samples in the destruction of $\mathrm{MB}^{+} \mathrm{Cl}^{-}$.

\begin{tabular}{lccc}
\hline $\mathrm{TiO}_{2}$ samples & $\mathrm{S}_{\mathrm{sp}}, \mathrm{m}^{2} / \mathrm{g}$ & $\mathrm{k}_{\mathrm{d}}\left(\times 10^{4}\right), \mathrm{s}^{-1}$ & $\mathrm{k}_{\mathrm{d}} / \mathrm{S}_{\mathrm{sp}}, \mathrm{g} \mathrm{s}^{-1} \mathrm{~m}^{-2}$ \\
\hline $\mathrm{A}$ & 95 & 0.9 & 0.0095 \\
$\mathrm{~A}$ & 199 & 2.2 & 0.0112 \\
$\mathrm{R}$ & 3 & 0.4 & 0.133 \\
$\mathrm{R}$ & 95 & 0.3 & 0.0032 \\
19\%A 81\%R & 54 & 0.6 & 0.0111 \\
30\%A 70\%R & - & 0.1 & - \\
40\%A 60\%R & 93 & 0.2 & 0.0022 \\
65\%A 35\%R & 195 & 1.1 & 0.0056 \\
80\%A 20\%R & 165 & 1.3 & 0.0079 \\
\hline
\end{tabular}

dichromate solution gives rise to a green $\mathrm{Cr}$ (III) compound water insoluble. Solution of potassium permanganate is decomposed by UV light to give brown $\mathrm{MnO}_{2}$ dispersion. Rate of the $\mathrm{MnO}_{4}{ }^{-}$decomposition is about 5 times faster with $\mathrm{TiO}_{2}$ present. Potassium ferricyanide is resistant to exposure to both visible and UV light over 3 hours. Addition of $\mathrm{TiO}_{2}$ to the aqueous ferricyanide solution being UV irradiated leave a dark-blue sedimentation of ferroferricyanide (Turnbullis Blue). UV irradiation of potassium ferrocyanide in the absence of $\mathrm{TiO}_{2}$ gives sediment of ferroferrocyanide (Prussian Blue). In the presence of $\mathrm{TiO}_{2}$, the reaction is nearly six times faster.

3.5. Kinetic of the photocatalytic reactions. All the investigated reactions obey the first order kinetics. The observed rate constants can vary by more than order of magnitude depending on nature of $\mathrm{TiO}_{2}$ and substrate (Tables 1-4). The rate constants of the above photocatalytic reactions are not dependent on mixing speed.

Rate constants of all the photocatalytic reactions are found to depend on $\mathrm{pH}$ of the solution. The photocatalytic reactions of $\mathrm{TDPy}^{+} \mathrm{Cl}^{-}, \mathrm{MB}^{+} \mathrm{Cl}^{-}$and $\left[\mathrm{Fe}(\mathrm{CN})_{6}\right]^{3-}$ exhibit the highest rate constant in acidic solutions (Figure 3). The maximum rate constants were found at $\mathrm{pH} 7$ for the photocatalytic destruction of TCF and reduction of $\mathrm{Cr}_{2} \mathrm{O}_{7}{ }^{2-}$.

3.6. Photocatalytic activity of the gamma irradiated $\mathrm{TiO}_{2}$. The photocatalytic activity of the $\gamma$ rayed $\mathrm{TiO}_{2}$ has been studied in view of increasing

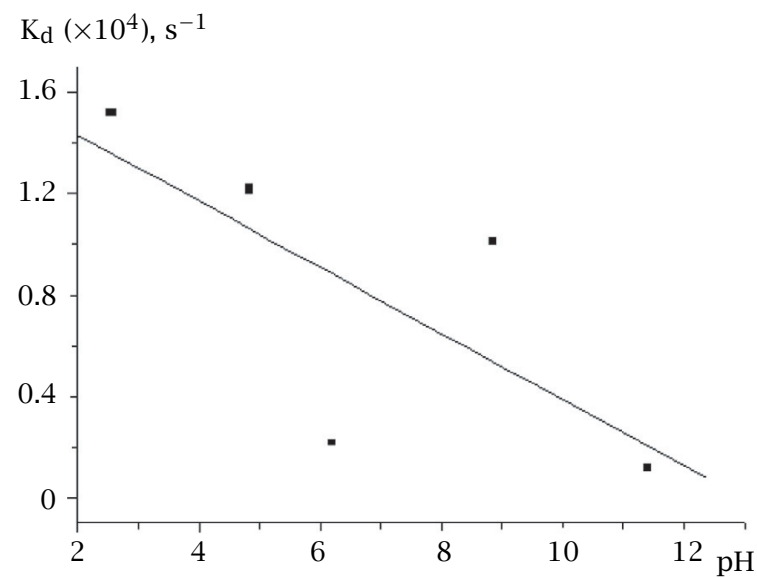

Figure 3. The dependence of $\mathrm{k}_{\mathrm{d}} v \mathrm{vs}$. $\mathrm{pH}$ for the destruction of $\mathrm{TDPy}^{+} \mathrm{Cl}^{-}$. 
Table 3. Photocatalytic activity of the $\mathrm{TiO}_{2}$ samples in the destruction of TCF.

\begin{tabular}{lccc}
\hline $\mathrm{TiO}_{2}$ samples & $\mathrm{S}_{\mathrm{sp}}, \mathrm{m}^{2} / \mathrm{g}$ & $\mathrm{k}_{\mathrm{d}}\left(\times 10^{4}\right), \mathrm{s}^{-1}$ & $\mathrm{k}_{\mathrm{d}} / \mathrm{S}_{\mathrm{sp}}, \mathrm{g} \mathrm{s}^{-1} \mathrm{~m}^{-2}$ \\
\hline $\mathrm{R}$ & 3 & 0.6 & 0.2 \\
$\mathrm{R}$ & 95 & 0.7 & 0.0074 \\
$65 \% \mathrm{~A} 35 \% \mathrm{R}$ & 195 & 1.8 & 0.0092 \\
$80 \% \mathrm{~A} 20 \% \mathrm{R}$ & 165 & 0.8 & 0.0048 \\
\hline
\end{tabular}

Table 4. Photocatalytic activity of the $\mathrm{TiO}_{2}$ samples in reduction of inorganic anions.

\begin{tabular}{|c|c|c|c|c|c|c|c|}
\hline \multirow[b]{2}{*}{$\mathrm{TiO}_{2}$ samples } & \multirow[b]{2}{*}{$\mathrm{S}_{\mathrm{sp}}, \mathrm{m}^{2} / \mathrm{g}$} & \multicolumn{2}{|c|}{$\mathrm{KMnO}_{4}$} & \multicolumn{2}{|c|}{$\mathrm{K}_{3}\left[\mathrm{Fe}(\mathrm{CN})_{6}\right]$} & \multicolumn{2}{|c|}{$\mathrm{k}_{2} \mathrm{Cr}_{2} \mathrm{O}_{7}$} \\
\hline & & $\begin{array}{c}\mathrm{k}_{\mathrm{d}} \times 10^{4}, \\
\mathrm{~s}^{-1}\end{array}$ & $\begin{array}{c}\mathrm{k}_{\mathrm{d}} / \mathrm{S}_{\mathrm{sp}} \\
\mathrm{g} \mathrm{s}^{-1} \mathrm{~m}^{-2}\end{array}$ & $\begin{array}{c}\mathrm{k}_{\mathrm{d}} \times 10^{4}, \\
\mathrm{~s}^{-1}\end{array}$ & $\begin{array}{c}\mathrm{k}_{\mathrm{d}} / \mathrm{S}_{\mathrm{sp}} \\
\mathrm{g} \mathrm{s}^{-1} \mathrm{~m}^{-2}\end{array}$ & $\begin{array}{c}\mathrm{k}_{\mathrm{d}} \times 10^{4}, \\
\mathrm{~s}^{-1}\end{array}$ & $\begin{array}{c}\mathrm{k}_{\mathrm{d}} / \mathrm{S}_{\mathrm{sp}} \\
\mathrm{g} \mathrm{s}^{-1} \mathrm{~m}^{-2}\end{array}$ \\
\hline A & 95 & 6.1 & 0.064 & 0.8 & 0.008 & 2.9 & 0.030 \\
\hline $\mathrm{R}$ & 95 & 0.2 & 0.002 & 1.3 & 0.014 & 2.8 & 0.029 \\
\hline $\mathrm{R}$ & 3 & 1.6 & 0.53 & 0.09 & 0.03 & 0.7 & 0.223 \\
\hline 40\%A 60\%R & 93 & 4 & 0.043 & 1.4 & 0.015 & 1.5 & 0.016 \\
\hline 65\%A 35\%R & 195 & 7.3 & 0.037 & 2.6 & 0.013 & 3.5 & 0.018 \\
\hline 75\%A 25\%R & 185 & 5 & 0.027 & 1.7 & 0.09 & 1.7 & 0.009 \\
\hline
\end{tabular}

catalytic activity of various solid substances in dark processes $[14,15]$. In this work, we established that prior $\gamma$-irradiation of the dispersed $\mathrm{TiO}_{2}$ rises rate of the photocatalitic destruction of both $\mathrm{TDPy}^{+} \mathrm{Cl}^{-}$and $\mathrm{MB}^{+} \mathrm{Cl}^{-}$at the optimum absorbed dose around $500 \mathrm{~Gy}$ (Table 5). The irradiated $\mathrm{TiO}_{2}$ samples did not change noticeably their photocatalytic activity within a month. The cause of the radiation effects could be the formation of the electron or hole defects on the particles surface or in the near-surface region as well as the generation of hot atoms or free radicals in the radiationinduced destruction of surface residues.

Table 5. Photocatalytic activity of the irradiated $\mathrm{TiO}_{2}$ samples in the destruction of $\mathrm{MB}^{+} \mathrm{Cl}^{-}$and $\mathrm{TDPy}^{+} \mathrm{Cl}^{-}$.

\begin{tabular}{lcccc}
\hline $\begin{array}{l}\text { Titanium } \\
\text { dioxide }\end{array}$ & $\begin{array}{c}\mathrm{S}_{\mathrm{sp}}, \\
\mathrm{m}^{2} / \mathrm{g}\end{array}$ & Dose, Gy & \multicolumn{2}{c}{$\mathrm{k}_{\mathrm{d}}\left(\times 10^{4}\right), \mathrm{s}^{-1}$} \\
\cline { 4 - 5 } & & - & $\mathrm{MB}^{+} \mathrm{Cl}^{-}$ & $\mathrm{TDPY}^{+} \mathrm{Cl}^{-}$ \\
\hline \multirow{2}{*}{$\mathrm{R}$} & \multirow{3}{*}{3} & 300 & 0.4 & 1.9 \\
& & 500 & 1.0 & 1.5 \\
& & 700 & 0.3 & 2.6 \\
& & - & 0.2 & 0.4 \\
40\%A 60\%R & \multirow{2}{*}{93} & 300 & 0.4 & 0.4 \\
& & 500 & 0.3 & 0.7 \\
& & 700 & 0.3 & Not done \\
\hline
\end{tabular}

\section{DISCUSSION}

Total combination of the facts obtained using the optical pure specimens allows providing an insight into the function of the $\mathrm{TiO}_{2}$ reactivity on adsorption, specific surface area and crystalline structure. Although the processes involving the above substrates are chemically distinct they share a number of traits, analysis of which may benefit for an active search of new photocatalytic agents around $\mathrm{TiO}_{2}$.
4.1. Correlation of photocatalytic and sorption properties of $\mathrm{TiO}_{2}$. Frequently occurring opinion is that the absorbed molecules are mainly subjected to photocatalytic transformation. This has let to believe (see, for instance, [14]) that photocatalytic activity may be related directly to sorption ability of $\mathrm{TiO}_{2}$ like the inorganic anions involved. The last-named statement should particularly apply to the processes involving electron transfer between $\mathrm{TiO}_{2}$ and substrate. Admittedly, the role of sorption was not studied for the majority of photocatalytic processes.

For the most reactions has been studied in this work, $\mathrm{k}_{\mathrm{d}}$ increases with increasing $a$ (Figure 4) although corresponding correlation coefficients were very small (Table 6). Correlation $\mathrm{k}_{\mathrm{d}}$ with adsorption is also lacking for the reactions of various substrates proceeding on a common photocatalyst (Figure 5). The TDPy ${ }^{+} \mathrm{Cl}^{-}$ destruction features an inversed dependence of $\mathrm{k}_{\mathrm{d}}$

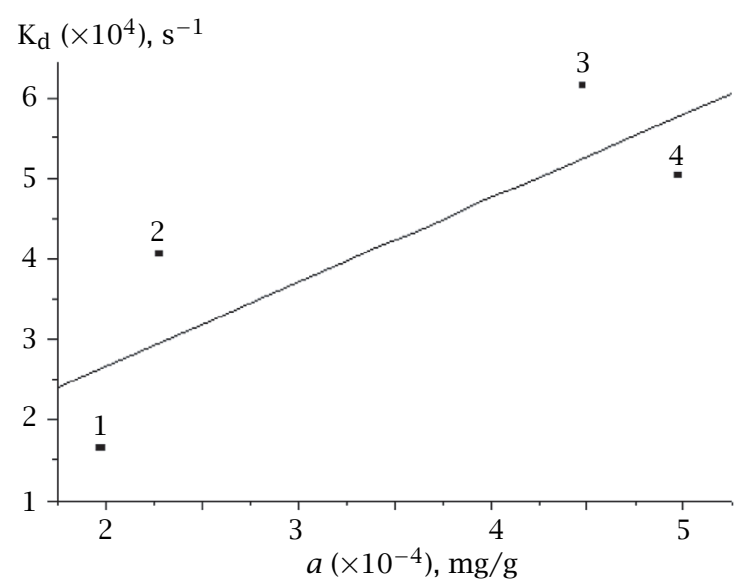

Figure 4. The correlation between $\mathrm{k}_{\mathrm{d}}$ and a for the photocatalytic reduction of $\mathrm{MnO}_{4}{ }^{-}$. 1-R, 2-40\%A $60 \% R, 3-A, 4-75 \%$ A $25 \%$. 
Table 6. Correlation coefficients $\mathrm{k}_{\mathrm{d}}$ with adsorption and specific surface area.

\begin{tabular}{lcc}
\hline \multirow{2}{*}{ Substrate } & \multicolumn{2}{c}{ Correlation coefficients } \\
\cline { 2 - 3 } & $a$ & $\mathrm{~S}_{\mathrm{sp}}$ \\
\hline $\mathrm{TDPy}^{+} \mathrm{Cl}^{-}$ & -0.72 & -0.32 \\
$\mathrm{MB}^{+} \mathrm{Cl}^{-}$ & 0.4 & 0.76 \\
$\mathrm{TCF}$ & 0.5 & -0.19 \\
{$\left[\mathrm{Fe}(\mathrm{CN})_{6}\right]^{3-}$} & 0.42 & 0.92 \\
$\mathrm{MnO}_{4}{ }^{-}$ & 0.6 & 0.66 \\
$\mathrm{Cr}_{2} \mathrm{O}_{7}^{2-}$ & 0.12 & 0.64 \\
\hline
\end{tabular}

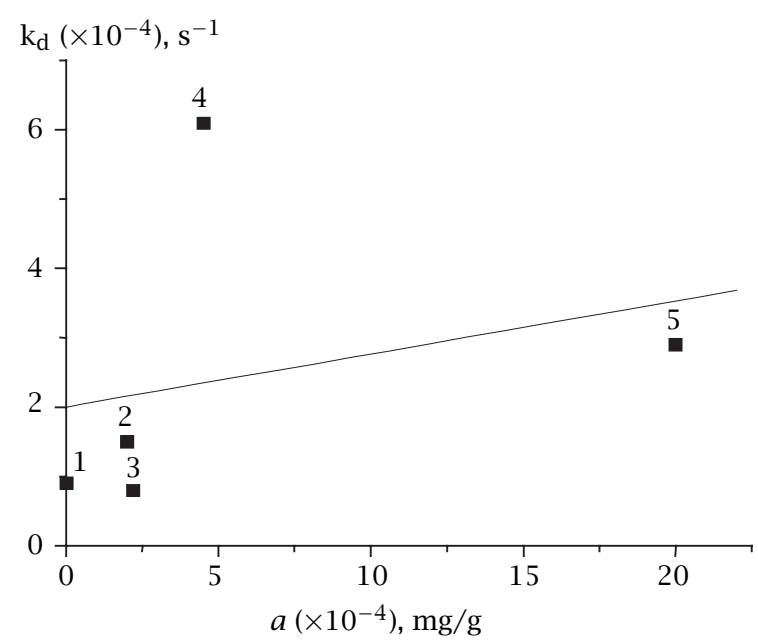

Figure 5. The dependence of $\mathrm{k}_{\mathrm{d}} v s$. a for the destruction reactions on anatase. $1-\mathrm{MB}^{+} \mathrm{Cl}^{-}, 2-\mathrm{TDPy}^{+} \mathrm{Cl}^{-}, 3-$ $\left[\mathrm{Fe}(\mathrm{CN})_{6}\right]^{3-}, 4-\mathrm{MnO}_{4}{ }^{-}, 5-\mathrm{Cr}_{2} \mathrm{O}_{7}{ }^{2-}$.

vs. a. Some $\mathrm{TiO}_{2}$ samples having small sorption capacity demonstrated high photocatalytic activity and conversely.

Besides, correlation was not found between rate constants and the time taken to the attainment of the equilibrium. UV Irradiation should disturb the system from the equilibrium state in systems with long time, taken to attainment of the sorption/desorption equilibrium, and high rate of photocatalytic reaction, for example, in the $\mathrm{TDPy}^{+} \mathrm{Cl}^{-} / \mathrm{TiO}_{2}$ systems. In such cases, however, rate constants did not noticeable reduce with time that also shows that sorption does not play a leading role in the reactions under study.

All these results are to allow conclusion that sorption properties are not governing factor for photocatalytic activity of $\mathrm{TiO}_{2}$ that may be attributable to the involvement of labile complexes between the substrates and the $\mathrm{TiO}_{2}$ surface in the photocatalytic reactions.

4.2. Photocatalytic activity and specific surface area. One popular statement resides in the fact that rate of photocatalytic processes can be essentially accelerated by increasing specific surface area, $\mathrm{S}_{\mathrm{sp}}$, of photocatalyst. In this connection, we analyzed the influence of this factor on rate constants of the above processes. Thereupon the question has been arisen whether the surface of the $\mathrm{TiO}_{2}$ pores should be taken into consideration. Reactions (6)-(8), which not only results in highly reactive species but also prevent the electron hole recombination, can proceed both in pores and outside area of the $\mathrm{TiO}_{2}$ particles. Therefore, the total specific surface area seems to be used in the calculations of the specific rate constants of the photocatalytic reactions on $\mathrm{TiO}_{2}$.

For the destruction of $\left[\mathrm{Fe}(\mathrm{CN})_{6}\right]^{3-}, \mathrm{k}_{\mathrm{d}}$ rises clearly as $S_{\text {sp }}$ increases (Figure 6). However, plausible link between $\mathrm{k}_{\mathrm{d}}$ and $\mathrm{S}_{\mathrm{sp}}$ is lucking in the majority cases. Interestingly that $\mathrm{k}_{\mathrm{d}}$ decreases with rising $\mathrm{S}_{\mathrm{sp}}$ for the destruction of $\mathrm{TDPy}^{+} \mathrm{Cl}^{-}$and TCF (Table 6). Negative correlation coefficients, while small in absolute value, were found for the processes involving only anatase, rutile or the two-phase modification.

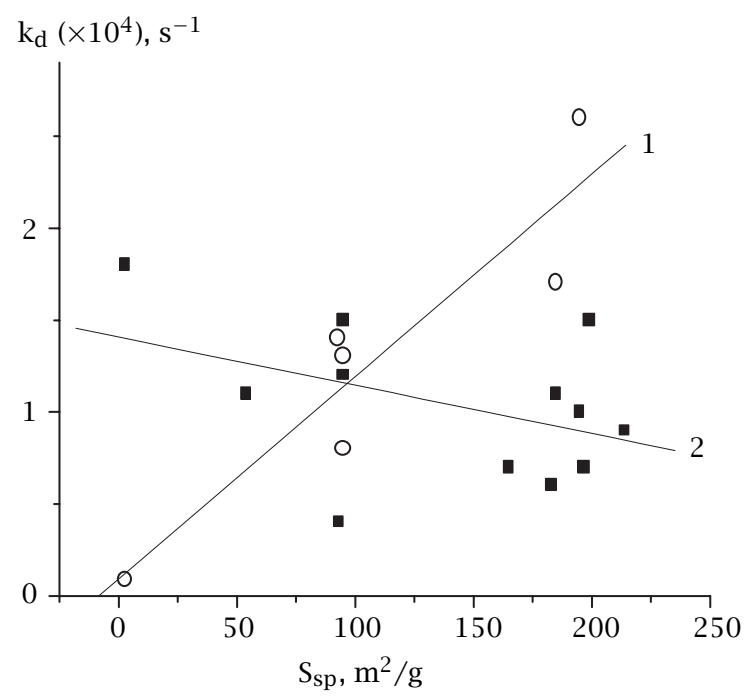

Figure 6. The dependence of $\mathrm{k}_{\mathrm{d}}$ vs. $\mathrm{S}_{\mathrm{sp}}$ for the photocatalytic reactions of $\left[\mathrm{Fe}(\mathrm{CN})_{6}\right]^{3-}$ (1) and $\mathrm{TDPy}^{+} \mathrm{Cl}^{-}$(2).

Rate constant of heterogeneous photocatalytic reaction should indubitably increase with specific surface area of a photocatalyst. In specific cases, such link can be masked by influence of stronger factors like crystalline structure, nature and concentration of residuals on $\mathrm{TiO}_{2}$ surface etc. However, the destruction of $\mathrm{TDPy}^{+} \mathrm{Cl}^{-}$discussed immediately above shows that correlation between $\mathrm{k}_{\mathrm{d}}$ and $\mathrm{S}_{\mathrm{sp}}$ can be lacking even for the catalysts having identical crystalline structure and treated in a similar manner. This phenomenon is dealt with in the next paragraph.

4.3. Influence of crystalline structure. Rate constants of the destruction reactions of the organic substrates being studied can differ not more than by 5-6 times depending on $\mathrm{TiO}_{2}$ nature (Tables 1-3). The influence of the $\mathrm{TiO}_{2}$ crystalline structure is stronger for the 
transformations of the inorganic anions, rate constants of which can differ in 30 times (Table 4).

The measure of photocatalytic activity of the $\mathrm{TiO}_{2}$ modifications can be specific rate constant, $\mathrm{k}_{\mathrm{d}} / \mathrm{S}_{\mathrm{sp}}$, according to the principles of reaction kinetics in heterogeneous systems. This measure has been used as a characteristic of photocatalytic reactions on $\mathrm{TiO}_{2}$ [16].

For all the reactions under study, the rutile calcinated at $1073 \mathrm{~K}$ exhibits the highest $\mathrm{k}_{\mathrm{d}} / \mathrm{S}_{\mathrm{sp}}$ (see Figure 7). Concentration of $\mathrm{OH}$-groups on the rutile surface is much less than that for anatase [18]. Hence specific activity of the $\mathrm{TiO}_{2}$ photocatalysts is not associated with surface concentration of hydroxyls. Probably surface concentration of $\mathrm{OH}$-groups is sufficient for trapping all the holes even on the rutile $\mathrm{TiO}_{2}$ surface or/and reactions (6) and (7) play prior role in the photochemical destruction.

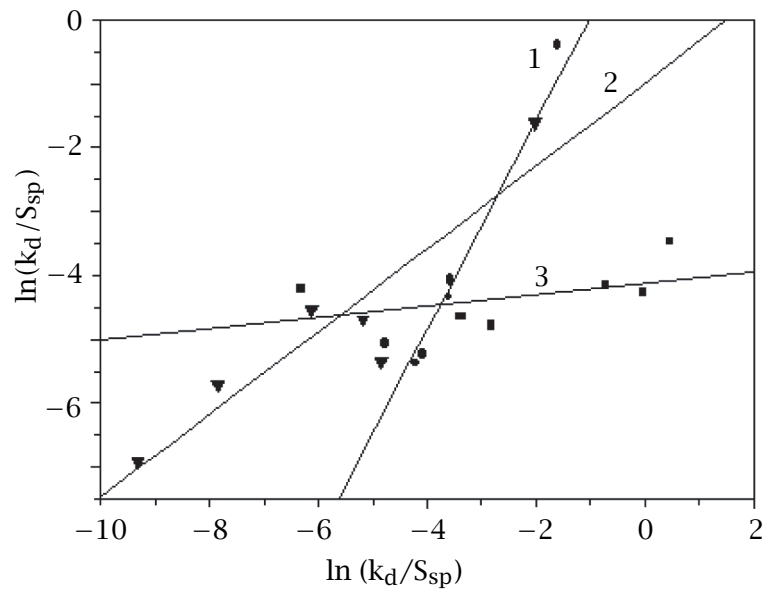

Figure 7. Correlations between specific rate constants for various pairs of the photocatalytic reactions. $1-\mathrm{Cr}_{2} \mathrm{O}_{7}{ }^{2-} / \mathrm{TDPy}^{+} \mathrm{Cl}^{-}, 2-\mathrm{MB}^{+} \mathrm{Cl}^{-} / \mathrm{TCF}, 3-\mathrm{MnO}_{4}{ }^{-}$/ $\left[\mathrm{Fe}(\mathrm{CN})_{6}\right]^{3-}$.

As opposite to rate constants, the links are revealed between $\mathrm{k}_{\mathrm{d}} / \mathrm{S}_{\mathrm{sp}}$, describing various reactions (Figure 7 ). Correlation coefficient exceeds 0.9 in most cases. On first inspection, the above pair correlations of $\mathrm{k}_{\mathrm{d}} / \mathrm{S}_{\mathrm{sp}}$ are surprising. However, they suggest that these all processes have common stages sensitive to crystalline structure.

The photocatalytic reactions involved are distinguished by responsivity towards alteration of $\mathrm{TiO}_{2}$ nature that can be illustrated with the help of Figure 7 . So, the $\mathrm{k}_{\mathrm{d}} / \mathrm{S}_{\mathrm{sp}}$ values are closely related to each other for the photocatalytic reduction of $\mathrm{MnO}_{4}{ }^{-}$regardless of the photocatalyst used in contrast to the reactions of $\mathrm{MB}^{+} \mathrm{Cl}^{-}, \mathrm{TCF}, \mathrm{Cr}_{2} \mathrm{O}_{7}{ }^{2-}$ and $\mathrm{TDPy}^{+} \mathrm{Cl}^{-}$.

Under low light intensity, the following relation holds for process rate, $v,[19]$

$$
v=\phi_{\mathrm{p}} \mathrm{I}_{\mathrm{a}} .
$$

where $\phi_{\mathrm{p}}=\eta_{\mathrm{r}} \eta_{\mathrm{i}} \eta_{\mathrm{p}} ; \eta_{\mathrm{r}}$ is the efficiency of the formation of the reactive electron-hole pair; $\eta_{\mathrm{i}}$ is the efficiency of the interfacial electron transfer; $\eta_{\mathrm{p}}$ is the efficiency of product formation; $I_{a}$ is light intensity.

The efficiency of the formation of the reactive electron hole pair should not be substrate dependent. The following expersion holds for $\eta_{\mathrm{i}}$

$$
\eta_{\mathrm{i}}=\mathrm{k}_{\mathrm{r}} /\left(\mathrm{k}_{3}+\mathrm{k}_{\mathrm{r}}\right)
$$

where $\mathrm{k}_{3}$ is rate constant of the electron hole recombination (3), $\mathrm{k}_{\mathrm{r}}$ is rate constant of primary product generation (reactions (4)-(8)). Interfacial electron-transfer rate constant is bound to rise with as the Gibbs free energy of electron transfer reduced in line with essential principle of electron transfer [20]. Thus, for very fast interfacial electron transfer $\mathrm{k}_{\mathrm{r}} \gg \mathrm{k}_{3}$ and $\eta_{\mathrm{i}}$ is invariant with $\mathrm{TiO}_{2}$ nature and specific surface. For such systems rate constants of photocatalytic reactions would be closely related for various $\mathrm{TiO}_{2}$ modifications. Apparently, this is true for photocatalytic reduction of $\mathrm{MnO}_{4}{ }^{-}$which is the strongest oxidant among the substrates studied.

Obviously $\eta_{\mathrm{p}}$ may be relatively independent of changes in $\mathrm{TiO}_{2}$ properties whereas $\eta_{\mathrm{r}}$ and $\eta_{\mathrm{i}}$ seem to change considerably. However, if the influence of $\mathrm{TiO}_{2}$ nature on $k_{d} / S_{s p}$ is specified by $\eta_{\mathrm{r}}$, all the correlations $\mathrm{k}_{\mathrm{d}}{ }^{\mathrm{y}} / \mathrm{S}_{\mathrm{sp}}{ }^{\mathrm{y}}$ vs. $\mathrm{k}_{\mathrm{d}}{ }^{\mathrm{x}} / \mathrm{S}_{\mathrm{sp}}{ }^{\mathrm{x}}$ should have a similar slope that is inconsistent with the experimental evidences (Figure 7). Only yield of the interfacial electron transfer hinges upon both nature of the photocatalyst and substrate. This gives reason to believe that $\eta_{\mathrm{i}}$ is the term which is the most sensitive to $\mathrm{TiO}_{2}$ properties and it defines principally influence of $\mathrm{TiO}_{2}$ and substrate on rate of examined photocatalytic reactions.

\section{REFERENCES}

[1] T. Minabe, D. A. Tryk, P. Sawunyama, Y. Kikuchi, K. A. Hashimoto, and K. Fujishima, J. Photochem. Photobiol. A: Chemistry 137 (2000), 53.

[2] R. Dillert, A. E. Cassano, R. Gosliach, and D. Bahnemann, Catalysis Today 54 (1999), 267.

[3] M. R. Hoffmann, S. T. Martin, W. Choi, and D. W. Bahnemann, Chem. Rev. 95 (1995), 69.

[4] T. Wu, G. Liu, and J. Zhao, J. Phys. Chem. 103 (1999), 4862.

[5] L. Lucarelli, V. Nadtochenko, and J. Kiwi, Langmuir 16 (2000), 1102.

[6] T. Keiichi, M. Capule, and H. Teruaki, Chem. Phys. Lett. 187 (1991), 73.

[7] Z. Luo and Q.-H. Gao, J. Photochem. Photobiol. 63 (1992), 367.

[8] V. V. Shimanovskaya, Physicochemical groundwork of preparation of optically pure titanium dioxide from hydrochloric solutions of titanium tetrachloride, Theses, Kiev, 1993. 
[9] A. A. Dverhyakova and L. E. Ivchenko, Ukr. Khim Zhurn. 53 (1977), 1014.

[10] V. V. Shimanovskaya, V. V. Strelko, and N. M. Torchun, Ukr. Khim Zhurn. 56 (1990), 1255.

[11] G. D. Parfitt and C. H. Rochester (Eds.), Adsorption from solution at the solid/liquid interface, Academic Press, London, 1983.

[12] C. H. Giles and T. H. McEwan, J. Chem. Soc. (1960), 3973.

[13] I. N. Martyanov and E. N. Savinov, J. Photochem. Photobiolog. A: Chemistry 134 (2000), 219.

[14] B. Ohtani, S. Zhang, J. Handa, H. Kajiwara, S. Nishimoto, and T. Kagiya, J. Photochem. Photobiol. 64 (1992), 223.
[15] M. Bideau, B. Claudel, L. Faure, and H. Kazouan, J. Photochem. Photobiol. 61 (1991), 269.

[16] A. Sclafani, L. Palmisano, and M. Schiavello, J. Phys. Chem. 94 (1990), 829.

[17] D. F. Ollis and H. Al-Ekabi (Eds.), Photocatalytical purification and treatment of water and air, Elsevier, Amsterdam, 1993.

[18] Z. Ding, G. O. Lu, and P. F. Greenfield, J. Phys. Chem. B 104 (2000), 4815.

[19] H. Kirsch, Adv. Photochem. 26 (2001), 93.

[20] A. M. Kuznetsov and J. Ulstrup, Electron transfer in chemistry and biology: an introduction to the theory, Wiley, London, 1998. 


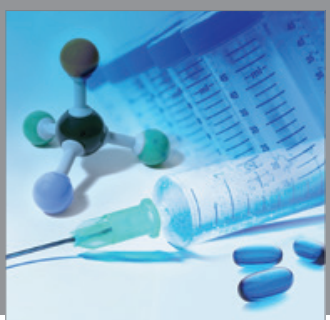

International Journal of

Medicinal Chemistry

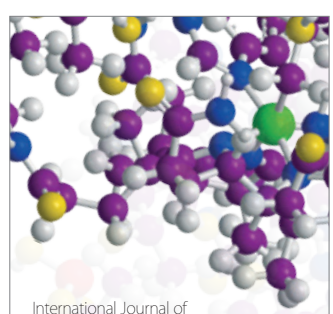

Carbohydrate Chemistry

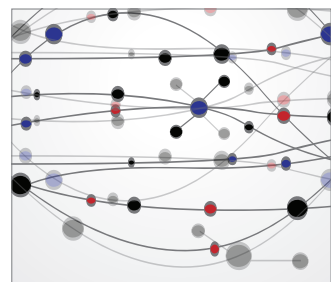

The Scientific World Journal
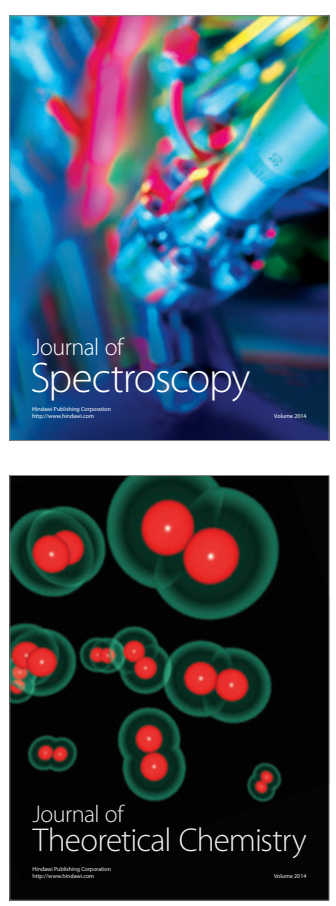
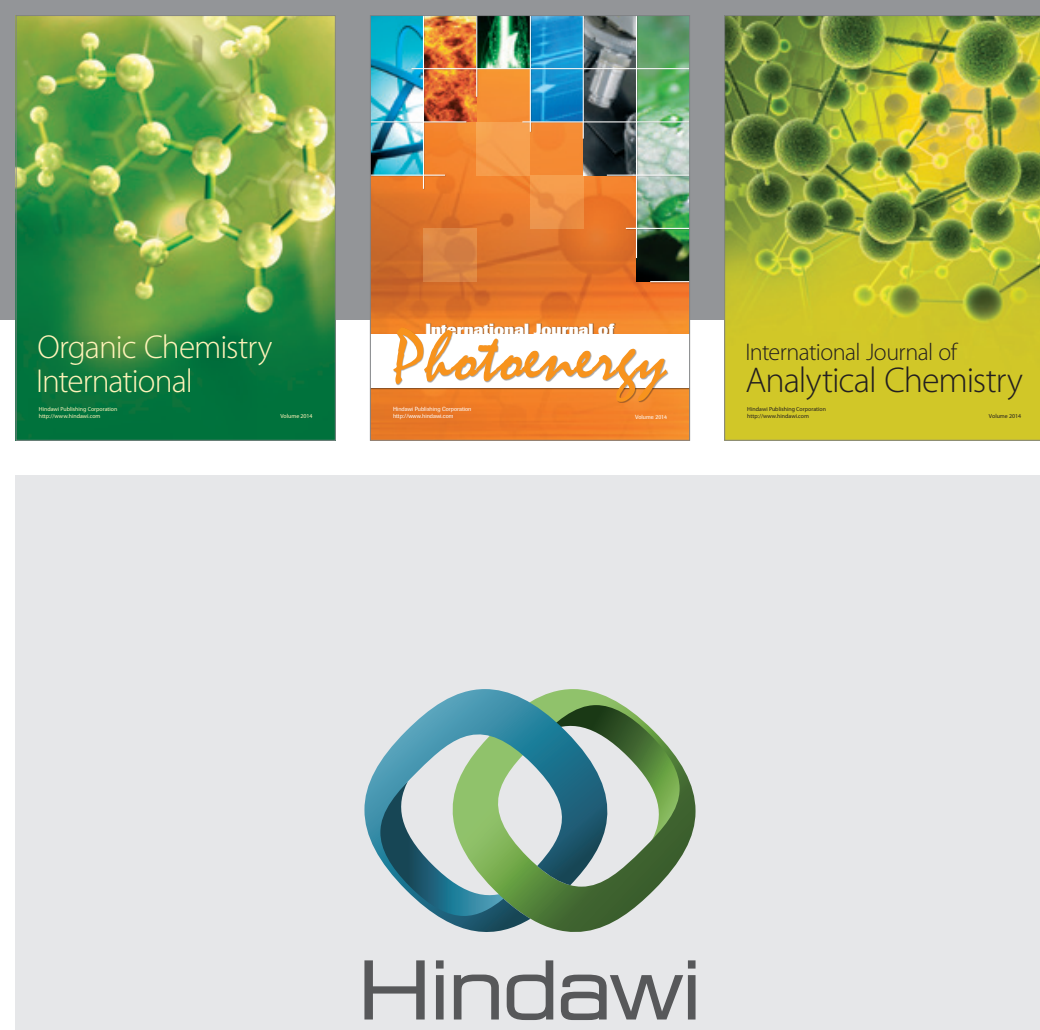

Submit your manuscripts at

http://www.hindawi.com
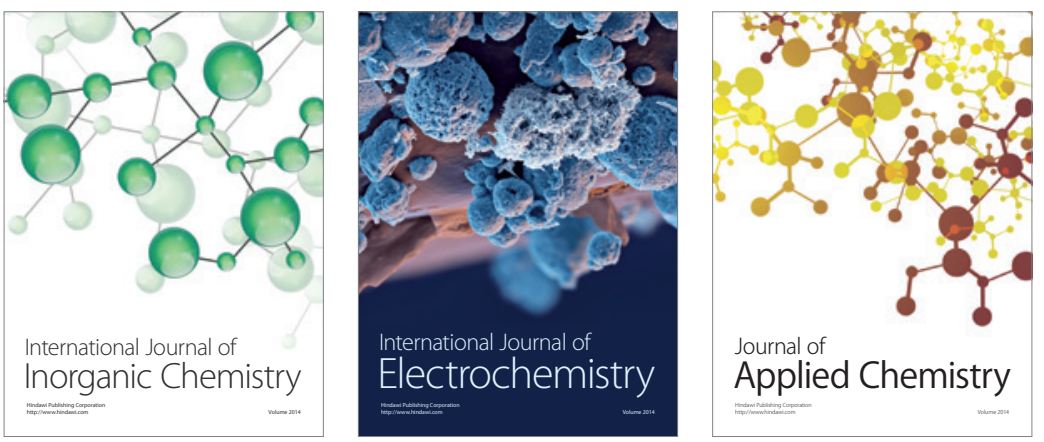

Journal of

Applied Chemistry
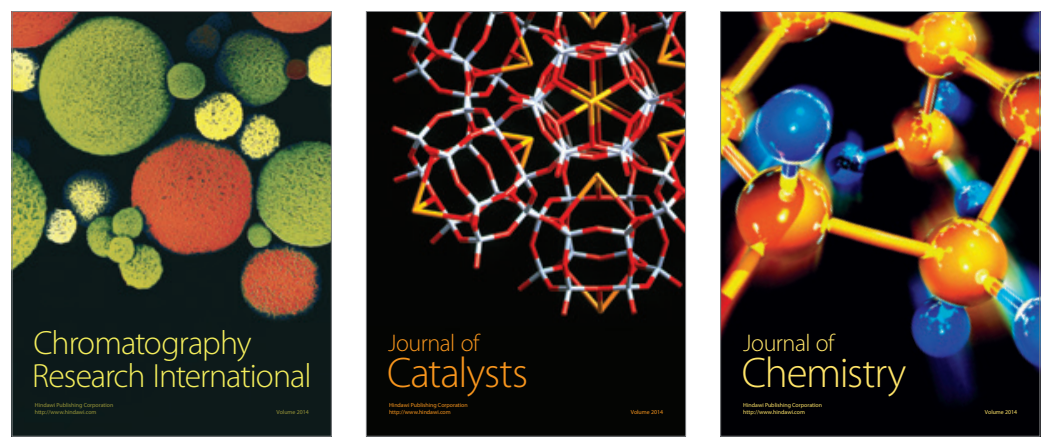
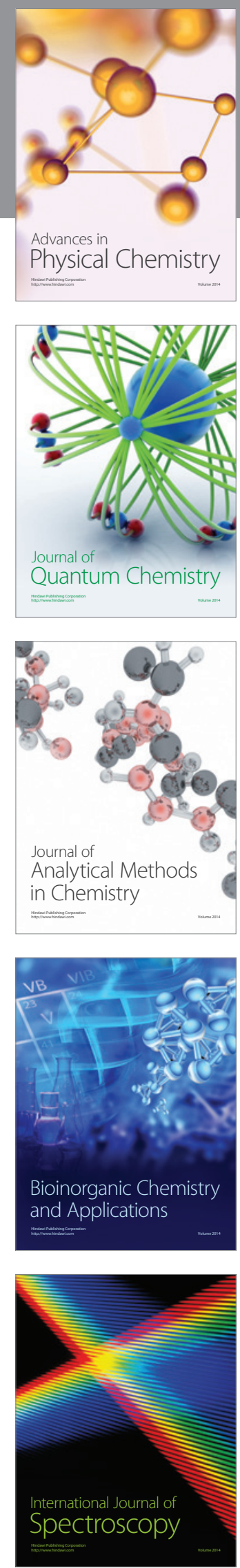